\title{
Homerske himne v slovenščini
}

\section{Boris Šinigoj}

Homerske himne. Uredil Brane Senegačnik. Prevodi in uvodi Blaž Božič, Lara Unuk, Blaž Zabel in Polonca Zupančič. Spremne besede Brane Senegačnik, Blaž Zabel in Polonca Zupančič. Ljubljana: Družina, 2019. 335 strani, $60 €$.

Njim pa so vztrepetala srca $\mathrm{v}$ prsih ...

Himna 3 Apolonu, v. 524

Integralni komentirani prevod Homerskih himn, ki jih zdaj prvikrat lahko beremo $v$ slovenskem jeziku, je sredi prevladujočega trivialnega slovstva in pojemajočega duha $\mathrm{v}$ slovenski kulturi nedvomno izjemen dosežek tako na področju navdihnjenega oživljanja antičnega izročila kot tudi subtilnega ohranjanja in negovanja zbornega poetičnega jezika. V njem izpričuje osupljiv prevajalski talent in redko dovzetnost za religiozno intonacijo grških himničnih poezij, ki se sicer slogovno vpisujejo v Homerjevo epsko izročilo, najmlajša generacija klasičnih filologinj in filologov, ki so smelo zastavili skupni prevajalski projekt pod mentorstvom profesorja in urednika izdaje Braneta Senegačnika, tudi avtorja poglobljenih spremnih besedil »Homerske himne: mostovi med ljudmi in bogovi« in »Misteriji, ki so za zmeraj ostali misteriji«.

Pred bralcem se v ritmiziranem prostem verzu, ki kljub opustitvi šestomerne homerske stopice izvirnika, ali pa morda prav zaradi nje, izpričuje izjemno svež poetični naboj, zvrstijo zbrane himne olimpskim, pa tudi drugim grškim bogovom in polbogovom. Kratki uvodni himni Dionizu sledijo štiri daljše, posvečene Demetri, Apolonu, Hermesu in Afroditi, potem pa se do konca zbirke zvrstijo krajše, pri čemer nekatere štejejo vsega nekaj verzov. Med njimi poleg že omenjenih, Aresa, Artemide, Atene, Here, Hefajsta, Pozejdona, Zevsa, Hestije in Muz, srečamo tudi božanstva in polbogove, ki širijo olimpski panteon: htonično Mater bogov, arkadijskega Pana, arhaično Zemljo, mater 
vsega, Hiperionova otroka Helija in Seleno ter pobožene Asklepija, Herakleja in Dioskura.

Začnimo z daljšo Himno 2 Demetri, ki z razgibano večplastnostjo pripovedi o boginjinem neutolažljivem iskanju svoje v podzemlje ugrabljene hčerke Perzefone ne pritegne le največ sodobnih razlagalcev, ampak z opisom prihoda v starko preoblečene Demetre na elevzinski dvor prejme svoj odjek tudi v novejši poeziji in celo časopisju. $\mathrm{Na}$ osrednji zaplet te himnične epizode na prelomu preteklega stoletja

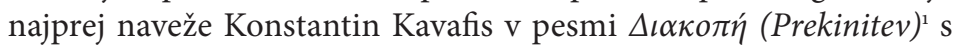
pomenljivim namigom na nespametno človeško vpletanje $\mathrm{v}$ delovanje bogov na primeru elevzinske kraljice Metanejre, ki podobno kot Pelej pri Tetidi v pretirani skrbi za sina usodno prekine boginjin postopek otrokovega poboženja v plamenih.

Himnični opis Demetrine zamere zaradi kraljičinega vpletanja, ki se izlije v napoved nesrečne usode Elevzincev, znova odjekne v časopisnem poročilu o skrivnostni starki, ki je sredi prejšnjega stoletja vstopila v avtobus na poti med Atenami in Korintom. ${ }^{2}$ Ker ni imela denarja za plačilo vozovnice, jo je sprevodnik odpravil z avtobusa ravno v mestu Elevzina. Toda voznik ni več mogel pognati vozila. Šele ko so potniki zbrali denar za njeno vozovnico in je spet vstopila, je avtobus speljal. Tedaj je starka spregovorila kot $\mathrm{v}$ prerokbi: »To bi morali storiti že prej, pa ste sebični, in ker sem že med vami, vam povem še nekaj: kaznovani boste za to, kako živite; ostali boste brez zelišč, celo brez vode!« In še preden je grožnjo izrekla do konca, je izginila.

Četudi nas mika, da bi opisanemu dogodku pripisali le naključno podobnost, ne gre zanikati oddaljene bližine med zaprepadenostjo potnikov in doživetjem svete groze, ki v homerski himni oblije Metanejro že ob prvem srečanju z Demetro, čeprav je v starki še ne prepozna. Kajti globlje kot sam motiv prerokbe nas zmore v zaključku himne nagovoriti razodetje nepogrešljive in daljnosežne vloge božjega

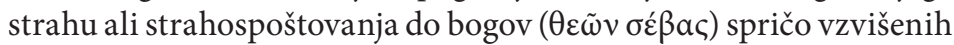
skrivnosti in svetih obredov, ki jih boginja v obliki misterijev vpelje v Elevzini. Doživetje božjega strahu posvečenim vanje ne odvzame le daru govora, ampak jih za vselej bivanjsko zaveže molku. Tako ohra-

1 Prim. Konstantin P. Kavafis, Zbrane pesmi, prevod, opombe in spremna beseda Dragica Fabjan Andritsakos (Ljubljana: KUD Logos, 2020), 30-31.

2 Poročilo iz časnika Hestia $\mathrm{z}$ dne 7 . februarja 1940 je $\mathrm{v}$ francoskem prevodu ohranil klasični filolog Charles Picard v članku »Déméter, puissance oraculaire«, Revue de l'Histoire des Religions 122 (1940), 102-103; navedeno po: Mircea Eliade, Zgodovina religioznih verovanj in idej, 2. knjiga, prev. Mojca Mihelič et al. (Ljubljana: Dzs, 1996), 245-46. 
nijo svete skrivnosti neoskrunjene, pomirijo božanstvo in obenem preženejo lastno grozo pred smrtjo ter se podobno kot vsaj za rodovitni del leta ljubljena Kori tudi sami rešijo zatohlega mrtvila podzemlja in postanejo deležni božanske blaženosti v življenju onkraj smrti.

$\mathrm{V}$ tem smislu pomeni Himna 2 Demetri dosti več od običajnega proojmiona k epski pesmi, kot sicer učinkuje krajša različica (13), ki šteje le tri verze, čeprav tudi v slednji naslovitev "vzvišena boginja «

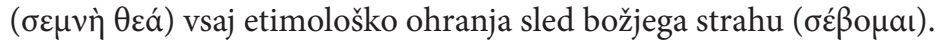

Dionizu so posvečene kar tri himne. Med njimi tematsko izstopa Himna 7 Dionizu ob sicer utečenih motivih o njegovem poreklu, slavni materi Semeli in dvojnem rojstvu iz Zevsovega stegna ter razvpitem "vlivanju blaznosti v ženske« in hrupnem sprevodu nimf pod vodstvom »bršljanolasega gromovnika" v preostalih dveh himnah $(1,26)$. V njej je podana zgodba o tirenskih pomorščakih, ki ugrabijo Dioniza v podobi kraljevskega mladeniča, vendar ga ujeti v pohlepno objestnost in napuh (üßpıৎ) ne prepoznajo. Kot v Platonovi prispodobi o ladji iz Politeje ostane priseben le umni krmar: ko v ugrabljenem prepozna (voj́бac) boga, v slutnji nesreče roti može, naj ga nemudoma spustijo na kopno. Toda vodja (ảpxó - prevod ga pomotoma zamenja s krmarjem), ki se nadeja dobička od ugrabitve, ga osorno zavrne in ukaže razpeti jadro. Tedaj se zvrstijo čudežni dogodki, ki zaprepadenim mornarjem razodenejo Dionizovo božansko naravo. Na krov privre sladko vino $\mathrm{z}$ vonjem po ambroziji, vinska trta $\mathrm{z}$ zrelimi grozdi in črn bršljan, obložen s cvetovi in plodovi, ovijeta jambor, venci prerasejo odprtine za vesla, sredi krova se ustopi besna medvedka, sam Dioniz pa se na premcu spremeni v rjovečega leva. Ko lev zgrabi vodjo, ostali možje pred zlo usodo poskačejo v morje, kjer se spremenijo v delfine. Božje usmiljenje se dotakne le preudarnega krmarja, ki mu zdaj razodeti Dioniz nakloni »najvišji blagoslov« ( $\pi \alpha v o ́ \lambda \beta ı o v)$.

Poleg Dioniza so tri himne posvečene le še boginji ljubezni, Afroditi, in Apolonu, pri čemer se mu v naslovu tretje pridružijo Muze. V obsežni Himni 3 Apolonu je izročilo zaradi motivske "podvojenosti« razbralo dva sklenjena himnična speva: »Delijskemu Apolonu«, ki opeva Apolonovo rojstvo na skalnatem otoku Delosu, kjer mu mati Letoja izvoli tudi prvi »sveti okraj« ( $\{\dot{\varepsilon} \mu \varepsilon v o \varsigma)$, in »Pitijskemu Apolonu«, ki poje o dramatični ustanovitvi Fojbovega svetišča v Delfih. Kot celota himna poleg omenjenih dveh $\mathrm{v}$ sklepnem delu opeva še tretji glavni dogodek, iniciacijo kretskih mornarjev za prve delfske svečenike. Tu se Apolon, ki v začetnih verzih obeh glavnih spevov pride na Olimp kot veličastno božanstvo, prvič z ozarjenim lokom in drugič z uglajeno formingo ( $\varphi$ ó $\mu \mu ү \xi)$, nenadejano pojavi v domala zaobrnjeni Himni 7 
Dionizu, ko v podobi delfina nenadoma skoči na kretsko ladjo in ugrabi njene mornarje za svečenike svojega novega delfskega svetišča.

Če pustimo ob strani Apolonov zmagoslavni poboj delfske zma-

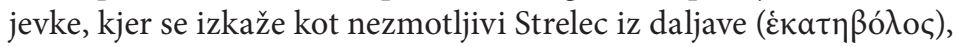
v himni vedno bolj stopa v ospredje v vlogi Kitarista, kar nakazuje že verz 131, v katerem si komaj rojeni bog najprej izvoli kítharis (v prevodu liro) in šele nato lok. To vlogo še utrdi z ubiranjem forminge (glagol

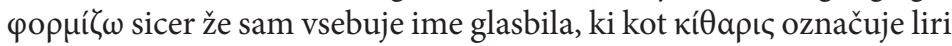
sorodno homersko brenkalo), ko v drugo prispe na Olimp. Ob milem odpevanju Muz nesmrtne v hipu povzdigne v zanos ter s čudovitim igranjem navsezadnje ugrabi srce tudi izvoljenim Krečanom in jim na poti v prostore svetišča, kamor bo dovoljeno vstopiti le njim, $\mathrm{z}$ božansko Muzo v prsi položi »medenozvenečo pesnitev«.

Tako ni presenetljivo, da v tudi kratki, heziodovsko intonirani Himni 25 Muzam in Apolonu srečamo Fojba predvsem v vlogi Glasbenika in voditelja Muz kot boginj navdiha, iz katerega se rojevajo

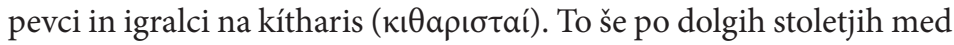
drugim prejme presunljivo doživet hiperborejski odjek v poemi Homo Muzagetes (Zimske Muze) sodobne sankpeterburške pesnice Elene Švarc. ${ }^{3}$ Še krajša Himna 21 Apolonu pa nas z motivom laboda (кúкvoৎ), ki Fojba "glasno opeva z zamahi peruti«, ponese celo onkraj dežele Hiperborejcev, kolikor spevno prhutanje labodjih peruti osupljivo odmeva v starodavni turkmenski legendi o Eflatunu (Platonu) kot iznajditelju glasbila dutar, ki ga je zasnoval, da bi posnemal čudovito zveneče prhutanje božanskega ptiča Kaknusa (Feniksa). ${ }^{4}$ In kot je nekoč »blagoglasni aojd z zvonko formingo $\mathrm{v}$ rokah vselej $\mathrm{v}$ začetku pa tudi na koncu « opeval Apolona, v ubranem zvenu azijskega dvostrunskega glasbila še danes odzvanja nesmrtni spev božanskih peruti.

Motiv glasbe znova stopi v ospredje v najdaljši izmed ohranjenih homerskih himn, Himni 4 Hermesu. Ta sicer izstopa po lahkotnejšem tonu in igrivih paradoksih, saj kakor v parodiji na svečano Himno 3 Apolonu drzno sprevrača njene motive. Tako se v nasprotju s Fojbovo zvesto predanostjo oznanjanju »nezmotljive Zevsove volje« Hermes ne

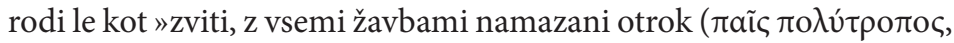

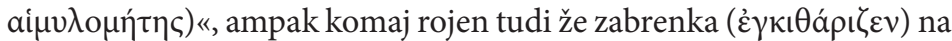
glasbilo, ki ga tik pred tem iznajde sam. Čim namreč zapusti rodno opombe in spremna beseda Boris Šinigoj (Ljubljana: KUD Logos, 2020), 134-53. Viktor Beliajev, Viktor A. Uspenski, Turkmenskaia muzyka (Moskva: Gos. Izd-vo muzykal'nyi sektor, 1928), 89; prim. B. Šinigoj, "Afganistanska glasba: petje slavcev med granatovci«, KUD Logos, 10. 4. 2021, dostopno na spletu. 
votlino, že iz želve ( $\chi \varepsilon ́ \lambda v \varsigma)$, ki ji nakloni ironične besede, »ko boš umrla, boš zelo lepo pela«, izdela glasbilo sedmerih strun ter ob njegovem strašnem zvenu, ki v smrtnih bitjih vzbuja sveto grozo, zapoje pesem o svojem božanskem poreklu.

Ko nadaljuje s čudežnimi deli ter se na krilatih sandalih zažene v predrzno krajo Apolonovega goveda, mu božanski sin preslavne Letoje (prevod ga v verzu 189 pomotoma pripiše Hermesovi materi Maji) nemudoma pride na sled. Vendar Fojba po dramatičnem soočenju mlajši brat Hermes navsezadnje pomiri z lepim petjem in brenkanjem na želvje glasbilo, ki je tu (v. 423) v celotnem korpusu Homerskih himn pravzaprav edinokrat v izvirniku izrecno imenovano lira $(\lambda u ́ \rho \alpha)$. Tedaj Hermes, čigar spevna umetnost ( $\tau \dot{\varepsilon} \chi \vee \eta)$ povsem prevzame Apolonovo srce, starejšemu bratu spravljivo podari želvje glasbilo, da bo odslej pod njegovimi spretnimi prsti ter v veščih rokah posvečenih aojdov venomer pričevalo o lepem in dobrem skladju vseh stvari, ki zmorejo poučiti in očarati um (vóoৎ).

$\mathrm{Ne}$ da bi se nadalje spuščali v podrobnejšo razčlembo Homerskih himn, se zdi, da na tem mestu vznikne temeljno vprašanje celotne zbirke, ki obenem zadeva najglobljo srčiko poezije kot take: vprašanje o izvornem smislu poezije. Ne le kolikor se v himnah nadvse pretanjeno prepletajo epski in lirski motivi, ampak tem bolj, kolikor se prav tu v himničnem zanosu na meji upovedljivega najgloblje razodeva skrivnost medsebojne povezanosti, ki se kakor nevidni most izteza prek brezdanjega prepada med božanskim in človeškim, med strašnim donenjem nebeške lire in sveto grozo človeka, med neubranljivo intonacijo od zgoraj in trepetom ugrabljenega človekovega srca spodaj, med nedosežnim muzičnim navdihom in uglasbenim spevom, ki se poraja iz njega, med nesmrtnim ubiranjem božanskih strun in smrtnimi trzaji zemskega brenkala.

To vprašanje dodatno osvetlijo še nekatere himne v zbirki. Med njimi je nedvomno ena najlepših Himna 5 Afroditi. V nasprotju s krajšima različicama 6 in 10, v katerih aojd opeva boginjino rojstvo iz morske pene in nesmrtno lepoto, ki osupne tudi bogove na Olimpu, vsebuje Himna 5 paradoksno razkritje boginjine lastne nemoči pred močjo ljubezni same. Po nagovoru Muzi, povzetem po začetnem verzu Odiseje, naj prične z opevanjem Afroditinih del, in treh krajših spevih, ki opevajo Ateno, Artemido in Hestijo kot edine, ki jim Kiprida v srcih ne more vzbuditi ljubezenskega poželenja, sledi osrednji spev. V njem Afrodita po Zevsovem naklepu sama podleže moči ljubezni, ko se nehote že na prvi pogled strahovito zaljubi v smrtnika, lepega pastirja Anhiza. Preden mu v spremstvu razvnetih zveri pohiti v objem, se v ciprskem svetem gaju tako ozaljša, da mladi pastir, ki ravno osamljen 
igra na kítharis, ob njeni lepoti zaprepaden ostrmi. Vendar je ne prepozna, prava epifanija božanstva napoči šele, ko ga boginja po opojni ljubezenski noči prebudi iz sna in se mu razodene v vsem božanskem veličastvu. Tedaj Anhiz doživi resnično prebujenje in vztrepeta v božjem strahu, da bo spričo storjenega ostal brez življenjske moči. Vendar mu Kiprida kljub sramoti, ki si jo je nakopala med nesmrtnimi bogovi, ker je podlegla ljubezni do smrtnika, nakloni ljubega sina Eneja, ki ga je spočela prevzeta od »strahotne bolesti«.

Med ostalimi olimpskimi bogovi sta nadalje po dve krajši homerski himni posvečeni trem boginjam, ki jih Afrodita ni mogla zapeljati v poželenje: Artemidi $(9,27)$, Ateni $(11,28)$ in Hestiji $(24,29)$. Četudi je obema himnama Artemidi skupno, da najprej opevata boginjo kot devico, ki siplje strelice, in mojstrico lova, ne gre prezreti, da se Himna 27 Artemidi sklene s plesom in pesmijo Muz in Harit pod boginjinim vodstvom na čast materi Letoji v delfskem svetišču. S tem aojd Apolonove sorojenke ne počasti le s Fojbovo muzagetsko vlogo, ampak v ospredje znova postavi božanski izvor pesništva, plesa in glasbe.

Pri himničnem opevanju Palade pa poleg značilnih epitetov boginje boja in modrosti, kot so »sovjeoka«, "preudarnega uma«, »devica«, "tritogeneja in podobno, v daljši Himni 28 Ateni, ki motivno nadgrajuje krajšo različico (11), znova nepogrešljivo stopi v ospredje doživetje božjega strahu ( $\sigma \varepsilon ́ \beta a \varsigma)$, tokrat v obliki, ki zbuja zaprepadenost. Sveta groza ob zlato ozarjenem boginjinem rojstvu iz Zevsove glave $v$ popolni bojni opravi namreč povsem nenadejano prevzame nesmrtne olimpske bogove same.

Kratki himni, ki sta posvečeni Hestiji, čaščeni zavetnici domačega ognjišča, h kateri so se praviloma najprej obračali v molitvah in ji vselej naklonili pitno daritev kot prvi in zadnji med nesmrtnimi bogovi, nas nato vrneta v Apolonovo in Hermesovo bližino. V Himni 24 Hestiji namreč boginja v aojdovi prošnji nastopi kot skrbnica Fojbovega svetega domovanja v Delfih, ki naj v spremstvu modrega Zevsa $\mathrm{z}$ naklonjenim srcem in milostjo pospremi njegovo pesem. Himna 29 Hestiji pa dostojanstveno Kronosovo prvorojenko, ki je na prvem mestu ne častijo le v bivališčih umrljivih ljudi, temveč tudi v domovih nesmrtnih bogov, $\mathrm{v}$ sklepni prošnji za podporo umnosti in mladostni

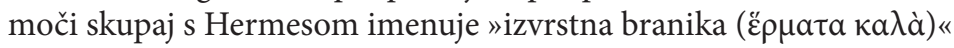
umrljivih ljudi, ki utrpevamo minljivost in tegobe življenja na zemlji.

S htonično Himno 14 Materi bogov v ospredje znova stopi glasba, ki s truščem tolkal, pomešanim s predirljivimi zvoki avlosov in rjovenjem divjih zveri ter odjekom $\mathrm{z}$ gora in gozdnatih gajev, $\mathrm{v}$ nasprotju $\mathrm{z}$ apolinično ubranostjo tokrat $\mathrm{v}$ vsega nekaj verzih silovito razkrije svojo neukročeno ekstatično plat. Toda ta svoje dopolnitve v zbirki Homer- 
skih himn paradoksno ne doseže v opevanju dionizične razbrzdanosti, ampak v arkadijski Himni 19 Panu. Še več, v idiličnem napevu trstenk Hermesovega kozonogega sina, dvorogega boga arkadijskih pastirjev in gorskih nimf, se vedno bolj prepletata htonično in božansko počelo, vse dokler himne ne sklene Panova apoteoza na Olimpu, kjer nesmrtni bogovi z Dionizom na čelu sinjegrivega dajmona v Hermesovem naročju $\mathrm{z}$ veseljem sprejmejo medse.

V Homerskih himnah seveda ne manjka tudi drugih religioznih motivov, ki povezujejo delovanje nesmrtnih bogov z življenjem umrljivih ljudi. Tako v Himni 20 Hefajstu srečamo poudarek na vzgoji ljudi; ti naj ob pomoči svetlooke Atene ne živijo kakor zveri, ampak naj obvladajo »sijajne veščine«, ki jim omogočajo dostojno življenje v miru. Sklepna prošnja za srčno ohranitev "nenevarne postave miru « odlikuje tudi orfiško navdihnjeno Himno 8 Aresu, ki poleg miroljubne naravnanosti izstopa tudi slogovno, in sicer z bujnim nizanjem epitetov nadvse bojevitega »branitelja Olimpa«. V Himni 22 Pozejdonu pa izmed delovanj nesmrtnih bogov $\mathrm{v}$ ospredje stopi še pomembnejša vloga rešenika $(\sigma \omega \tau \eta ́ \rho)$ ljudi v stiski na primeru morjeplovcev, ki z ladjo tonejo v viharju. Temu se pridružujeta tudi Zevsova dečka kot zvesta »rešitelja smrtnikov in jadrnih ladij« $\mathrm{z}$ dobrimi znamenji v podobi Elijevega ognja v sklepu Himne 33 Dioskuroma.

Najdrznejšemu med poboženimi heroji pa je posvečena Himna 16 Asklepiju, slovitemu Apolonovemu sinu, zdravilcu bolezni, ki se ni hotel zadržati le pri lajšanju bolečin, ampak si je po pričevanju izročila kakor v predpodobi novega življenja onkraj smrti drznil obujati mrtve. V tej luči tudi Sokratova predsmrtna prošnja Kritonu, naj Asklepiju ne pozabijo darovati petelina, ${ }^{5}$ prejme povsem nasproten pomen, kot mu ga po zgledu nesrečnega baselskega filologa pripišejo nedovzetni. Ne samo, da za filozofa življenje nikakor ni bolezen, ampak je, kolikor nas pripravlja na zagrobno življenje, nadvse dobrodošla vaja v umiranju ${ }^{6}$ - prav kakor so to že pred Platonom in njegovimi verovali tako misti v Elevzini kot tudi orfiki in pitagorejci.

Kaj naj sklenemo za konec? Čeprav se komu zdi, da Homerske himne predstavljajo le še filološko kurioziteto iz antičnih časov, ki se je po zaslugi neznanih prepisovalcev v srednjeveških skriptorijih in njihovih helenofilskih naslednikov po čudnem naključju ohranila vse do danes, dovzetnim dušam še vedno nudijo obilo duhovne spodbude in muzičnega navdiha. Nenazadnje Himna 22 Zevsu s poslednjo besedo o vrhovnem božanstvu kot »dovrševalcu vsega $\left(\tau \varepsilon \lambda \varepsilon \dot{\sigma} \sigma \varphi \rho_{0} \circ\right)$ ) prejme 
svoj simbolični odzven tudi $\mathrm{v}$ imenu slovitega kitarskega mojstra iz Valencije, ${ }^{7}$ ki je na prelomu preteklega stoletja v daljnosežnem apoliničnem zanosu pod svojim okriljem zbral vse najboljše izdelovalce kitar $\mathrm{z}$ domačega Olimpa. ${ }^{8}$

Zemlja, mati vsega, žena zvezdnatega neba, Hera, kraljica nesmrtnih, Herakles levjesrčni, žareči Helij, Selena širokih peruti ... Ah, bodi dovolj, o milozvočna Muza, prozaičnega ubiranja homerske lire, da smem zdaj tudi sam $\mathrm{k}$ drugi pesmi preiti.

7 Telesforo Julve Jordán (1887-1945).

8 Gre za slovito šolo luthierjev iz Valencije, ki je z odličnimi glasbili oskrbela številne kitariste po vsem svetu. James Greenberg, »Historic Guitar Makers of the Valencia School«, Zavaleta’s La Casa de Guitarras, 19. 5. 2015, dostopno na spletu. 